\title{
An Efficient Algorithm with Reduced Delay in Body Area Networks
}

\author{
Ayatollahitafti, V. \\ Department Computer System \& Communications \\ Universiti Teknologi Malaysia \\ UTM Skudai, Johor, Malaysia.
}

\author{
Ngadi, M.A. \\ Department Computer System \& Communications \\ Universiti Teknologi Malaysia \\ UTM Skudai, Johor, Malaysia.
}

\begin{abstract}
BANs(Body Area Networks) are networks which use different sensors for controlling status of patients. In this networks , according to type of disease and medical observation, sensors put on the patient's body and he or she can be controlled on pressure,body temperature and so on. One problem for doctors is the information that is sent with delay. Sending the information with delay is caused death of thousands patients in the world. In this paper , one hospital health care is considered that routing between nodes was carried out with normal olsr, and in another time selecting MPR nodes was carried out with minimum delay between source node and MPR node(proposed algorithm). Then delay in the network was calculated with two above methods. Results showed that delay in the proposed algorithm was less than normal algorithm. For simulation, opnet was used.
\end{abstract}

\section{Keywords}

OLSR , BAN , Delay ,proposed OLSR .

\section{INTRODUCTION}

WSNs are made up of sensors that use wireless transmission. BANs are kind of WSN which put in human body for health monitoring. They can be set up anywhere because they require neither infrastructure nor central administration. Wireless sensor networks can be effectively used in healthcare to enhance the quality of life provided for the patients and also the quality of healthcare services [1]. For example, patients equipped with a body sensor network (BSN) need not be physically present at the physician for their diagnostic. A body sensor network proves to be adequate for emergency cases, where it autonomously sends data about patient health so that physician can prepare for the treatment immediately [2-3].

There are some challenges in body sensor networks such as energy, Quality of Service, mobility, privacy, security,routing, reliability, and so on[4][5].

The overall routing protocol types responsible for transmission of packets between different mobile hosts in adhoc network falls into three broad categories[6]. The paper evaluates QoS with wireless sensor network routing protocols. The paper focused on three main protocols AODV, OLSR and TORA. Their work focused on routing performance with lower network congestion and with fixed number of nodes. They argued that OLSR is the most favourite proactive protocol and AODV is the most effective on-demand protocol within their environment. [7]presents Performance of
Wireless Body Sensor based Mesh Network for Health Application. [8] presents a biomedical sensor network model and evaluates energy consumption, packet reception ratio, network capacity, connectivity and delay.[9]presents a routing strategies for delay tolerant networks. In the another paper the performance analysis of different routing protocols based on their effect on the QoS by using CBR application in Zigbee network using static IEEE 802.15.4 is studied. QoS parameters such as data packet delivery ratio, average end-toend delay, jitter, and throughput are investigated as the metrics[10]. Some papers work on cluster based routing[11]. In this kind of algorithms routing is done by node clustering. Each cluster has a cluster head. Cluster head selection is an issue, Cluster head selection can be done by energy consuming[12]. The LEACH (Low Energy Adaptive Clustering Hierarchy) randomly selects nodes as a cluster head[13]. Some routing algorithms are related to thermal aware routing algorithms[14-17].

In this paper we use a modified OLSR routing protocol for BAN in hospital care. Delay between nodes is the parameter that we calculate it and evaluate network with this parameter. This research is carried out using software known as OPNET Modeler version 14. It provides a parallel kernel to support the increase in stability and mobility in the network.

The nodes were randomly placed within certain gap from each other in $1000 \times 1000 \mathrm{~m}$ environment in hospital care for 5 and 15 patients and each person has 8 sensors. Every scenario in the network was configured to execute OLSR and proposed OLSR. The simulation time was set to 300 s.

\section{AD HOC ROUTING PROTOCOLS}

\subsection{DSR( Dynamic Source Routing)}

DSR [18] is a reactive protocol i.e. it doesn't use periodic advertisements. It computes the routes when necessary and then maintains them. Source routing is a routing technique in which the sender of a packet determines the complete sequence of nodes through which the packet has to pass; the sender explicitly lists this route in the packet's header, identifying each forwarding "hop" by the address of the next node to which to transmit the packet on its way to the destination host. 


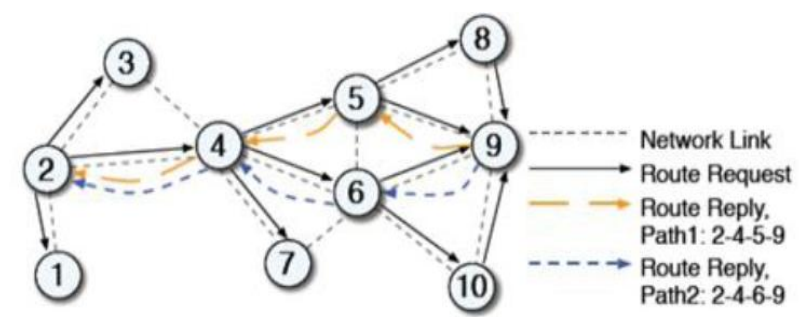

Fig. 1. DSR routing protocol[19]

\subsection{AODV(Ad Hoc On-demand Distance- Vector Protocol)}

AODV offers low network utilization and uses destination sequence number to ensure loop freedom. It is a reactive protocol implying that it requests a route when needed and it does not maintain routes for those nodes that do not actively participate in a communication. [20-21].

\subsection{Optimized Link State Routing Protocol (OLSR)}

This protocol works in collaboration with other nodes through the exchange of topology information. This exchange of information is done periodically. To avoid the broadcast of unnecessary packet re-transmissions, this protocol uses multipoint relays. In a network, a node broadcasts a message periodically to its neighboring nodes. This is done to compute the multipoint relay set as well as the exchange of information about the neighborhoods. From the information about the neighborhood this node calculates the minimum set of one hop relay point that is needed to reach the two hop neighbors and this set is called the Multipoint relay set. OLSR differs from link state protocols in two factors based on the dissemination of routing information. First is by construction i.e. only the multipoint relay nodes of a node A need to forward updates about link state that are issued by A. Secondly the size of the link state update of a node A is reduced because it only consists of those neighbors that selected node A as their multipoint relay node. Thus we can conclude that OLSR reduces the Link state protocol. It is used in a network where nodes are densely deployed; the OLSR calculates the shortest path in such networks to an arbitrary destination[22].

Finding a MPR set with minimal size falls in the category of dominating set problems, which are known to be NPcomplete. Demonstrations and proofs were detailed in [23]. The information needed to calculate MPRs is the set of onehop neighbors and two-hop neighbors. The proposed heuristic into calculate multipoint relay set of node $\mathrm{x}$ is as follows:[2425]

- Step 1: Start with an empty multipoint relay set MPR(x).

- Step 2: Calculate D(x,y), "nodes y $2 \mathrm{~N}(\mathrm{x})$.

- Step 3: First, select those one-hop neighbor nodes in N(x) as multipoint relays which provide the "only path" to reach some nodes in $\mathrm{N} 2(\mathrm{x})$, and add these one-hop neighbor nodes to the multipoint relay set MPR(x).

- Step 4: While there still exist some nodes in N2(x) that are not covered by the multipoint relay set $\operatorname{MPR}(\mathrm{x})$ :

- Step 4a: For each node in $\mathrm{N}(\mathrm{x})$ which is not in MPR(x), calculate the number of nodes that are reachable through it among nodes in $\mathrm{N} 2(\mathrm{x})$ and which are not yet covered by $\operatorname{MPR}(\mathrm{x})$.

- Step 4b: Select the node from N(x) as a MPR that reaches the maximum number of uncovered nodes in $\mathrm{N} 2(\mathrm{x})$.

- Step 5: To optimize, remove each node in $\operatorname{MPR}(\mathrm{x})$, one at a time, and check if MPR(x) still covers all nodes in N2(x).

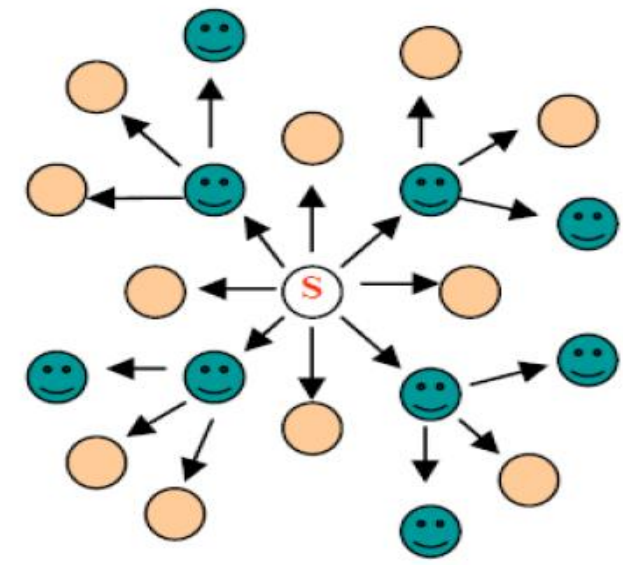

Fig. 2. The MPR flooding mechanism

\subsection{Proposed OLSR}

In proposed OLSR, algorithm was changed as below:

- Step 4: While there still exist some nodes in N2(x) that are not covered by the multipoint relay set $\mathrm{MPR}(\mathrm{x})$ :

- Step 4a: For each node in $\mathrm{N}(\mathrm{x})$ which is not in $\operatorname{MPR}(\mathrm{x})$, calculate delay $\mathrm{x}$ to $\operatorname{MPR}(\mathrm{x})$. Node with minimum delay is selected.

\section{PERFORMANCE METRICS}

We evaluated key performance metrics for two different networks using OLSR and proposed OLSR. We used the following parameters for evaluating the effect delay.

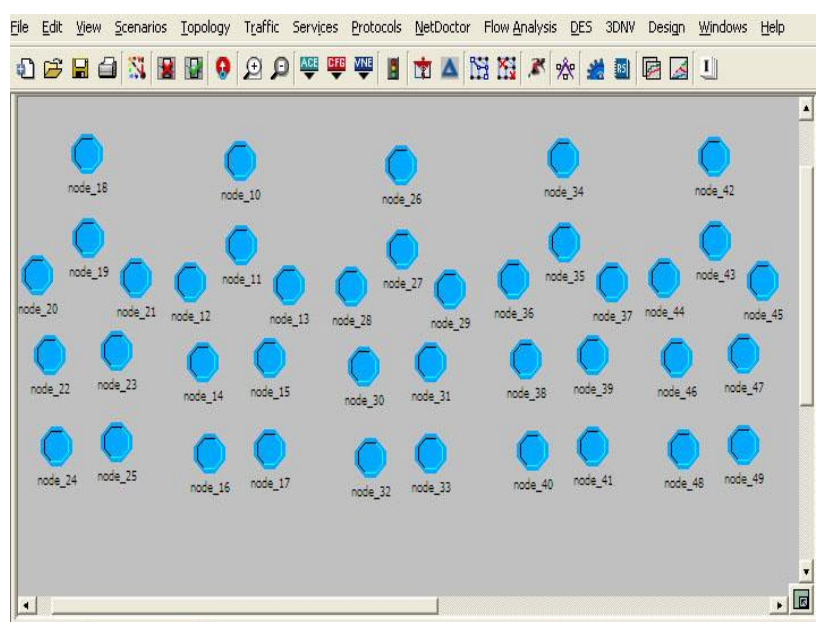

Fig. 3. A proposed model of BAN 
The network designed consists of basic network entities with the simulation parameters presented in table I.

Table I .Parameters of simulation

\begin{tabular}{|c|c|}
\hline Simulation time & $300 \mathrm{~s}$ \\
\hline Simulation area & $1000 * 1000 \mathrm{~m}$ \\
\hline Number of patients & 5,15 \\
\hline Data rate(bps) & $11 \mathrm{mbps}$ \\
\hline Mobility algorithm & Random waypoint \\
\hline Routing protocols & Olsr,proposed Olsr \\
\hline Performance parameter & Delay \\
\hline
\end{tabular}

\section{Simulation and discussion}

Our protocol evaluations are based on the simulation using OPNET simulator[26]. The scale up network model consists of 5,15 patients distributed randomly in a space of $1000 \mathrm{~m} \mathrm{X}$ $1000 \mathrm{~m} .[27]$

BAN for 5 patients :

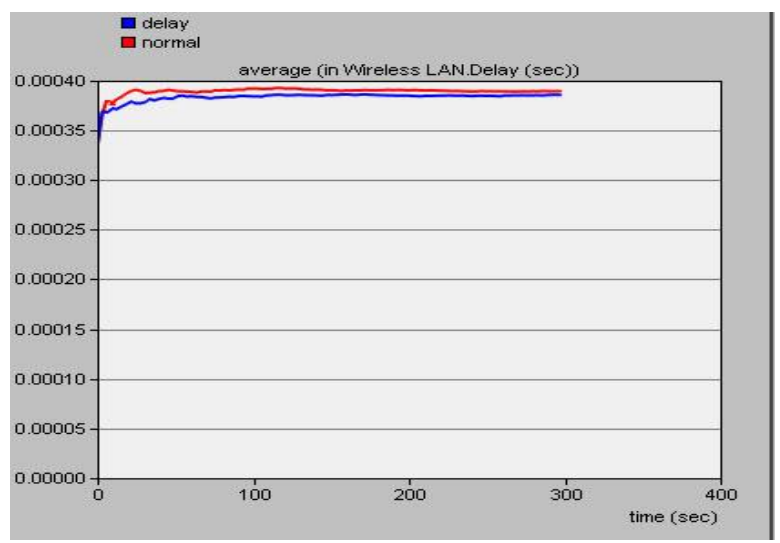

Fig.4 . delay for 5 patients

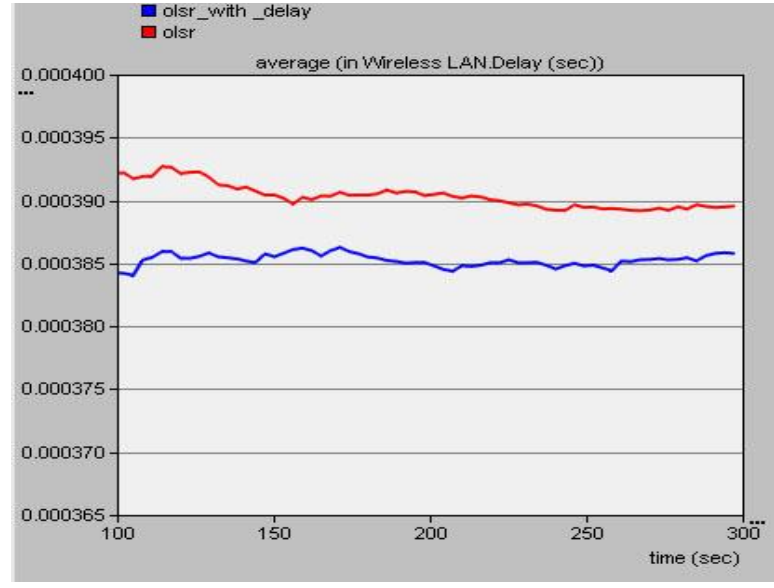

Fig.5 . delay for 5 patients (zoomed chart)

Fig. 4,5 show the end-to-end delay for each protocol. Average delay for OLSR is 0.00039 and for proposed OLSR is 0.000385 . Proposed OLSR has lower delay compared to normal OLSR.

BAN for 15 patients :

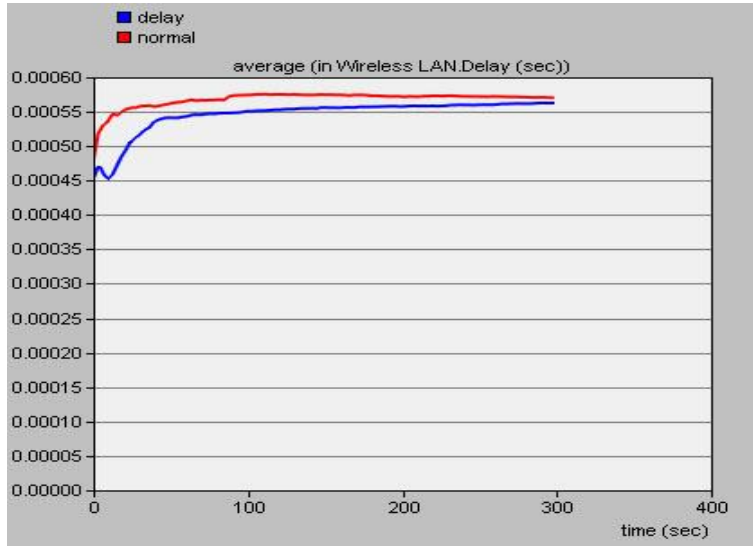

Fig. 6 . delay for 15 patients

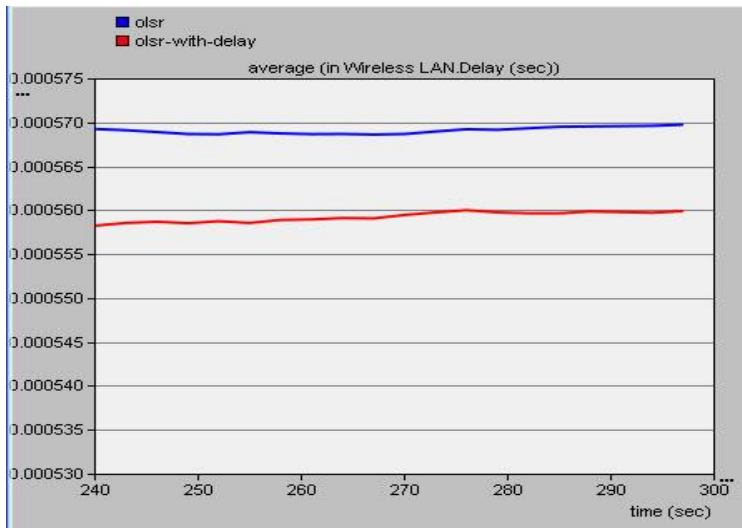

Fig. 7 . delay for 15 patients (zoomed figure) 
Fig. 6,7 show the delay for each protocol. Delay in OLSR is 0.000580 and for proposed OLSR is 0.000570 . Proposed OLSR for 15 patients has lower delay compared to normal OLSR.

\section{CONCLUSION}

In this paper, performance of OLSR and proposed OLSR was analysed using OPNET modeler 14. The protocols were tested using the same parameters with random mobility. Performance of protocols with respect to scalability has also analysed with delay.

Results showed that, with 5 patients proposed OLSR experienced lower delay compared to OLSR. This was due to delay between nodes and MPRs. Because MPR selecting is due to minimum delay between every nodes and other one hop nodes.With 15 patients proposed OLSR also experienced lower delay compared to OLSR. In BANs, because delay is very important, we can use proposed OLSR .

\section{References}

[1] U. Varshney,2007. "Pervasive Healthcare and Wireless Health Monitoring," Mobile Networks and Applications, vol. 12, pp.113-127.

[2] K. W. Goh, J. Lavanya, Y. Kim, E. K. Tan, and C. B. Soh, 2005. "A PDA-based ECG Beat Detector for Home Cardiac Care," in IEEE Engineering in Medicine and Biology Society, Shanghai, pp. 375-378.

[3] R. Hongliang, M. Q.-H. Meng, and X. Chen, 2005. "Physiological Information Acquisition Through Wireless Biomedical Sensor Networks," in IEEE international Conference on information Acquisition, pp. 483-488.

[4] Darwish, A.; Hassanien, A.E. 2011. "Wearable and implantable wireless sensor network solutions for healthcare monitoring." 11, 5561-5595, Sensors.

[5] B. Latr'e, B. Braem, I. Moerman, C. Blondia, and P. Demeester,2011. "A survey on wireless body area networks," Wireless Networks, vol. 17, no. 1, pp. 1-18.

[6] Qasim Nadia, Said Fatin \& Aghvami Hamid ,2009. "Mobile Ad Hoc Networking Protocol's Evaluation through Simulation for Quality of Service." - IAENG International Journal of Computer Science, 36:1, JCS_36_1_10, 17 February.

[7] N. A. Benjamin and S. Sankaranarayanan,2010. "Performance of Wireless Body Sensor based Mesh Network for Health Application", International Journal of Computer Information Systems and IndustrialManagement Applications (IJCISIM), Vol 2, pp. $20-28$.

[8] Dheerendra S. Gangwar,2011 . "TRAFFIC AND PERFORMANCE MANAGEMENT FOR BIOMEDICAL SENSOR NETWORK”, International Journal of Computer Science and Communication Vol. 2, No. 1, pp. 183-189.

[9] E.P. and Ward, P.A. 2006. 'Routing strategies for delaytolerant networks', Submitted to ACM Computer Communication Review (CCR).

[10] K Gurjit ,A Kiran , 2011.“QQos Measurement of Zigbee Home Automation Network using Various Routing
Protocols", International Journal of Computer Applications (0975 - 8887). Volume 13- No.2.

[11] M. Golam Rashed, M.Hasnat Kabir, Shaikh Enayet Ullah, 2010. "Cluster Based Hierarchal Routing Protocol For WSN" IJCNS, Vol.2, No.5.

[12] S.K. Singh, M.P. Singh, and D.K. Singh, 2010. "A survey of Energy-Efficient Hierarchical Cluster-based Routing in Wireless Sensor Networks", International Journal of Advanced Networking and Application (IJANA), vol. 02, issue 02, pp. 570-580.

[13] Honeine, P.; Mourad, F.; Kallas, M.; Snoussi, H.; Amoud, H.; Francis, C., 2011. "Wireless sensor networks in biomedical: Body area networks ", Systems, Signal Processing and their Applications (WOSSPA), 7th International Workshop.

[14] Daisuke Takahashi, Yang Xiao, Fei Hu, 2007. "LTRT: Least Total-Route Temperature Routing for Embedded Biomedical Sensor Networks", IEEE, 641-645.

[15] Anirban Bag and Mostafa A. Bassiouni, 2007. "Hotspot Preventing Routing Algorithm for Delaysensitive Biomedical Sensor Networks", IEEE, 1-5.

[16] Rossi Kamal, Md. Obaidur Rahman and Choong Seon Hong, 2011. "A Lightweight Temperature Scheduling Routing Algorithm for an Implanted Sensor Network", IEEE, 396-400.

[17] Qinghui Tang, Naveen Tummala, Sandeep K. S. Gupta, Loren Schwiebert, 2005. "TARA: Thermal-Aware Routing Algorithm for Implanted Sensor Networks", Distributed Computing in Sensor Systems,467-467.

[18] Rajeshwar Singh, Dharmendra K Singh, Lalan Kumar, 2011. " Performance Evaluation of DSR and DSDV Routing Protocols for Wireless Ad Hoc Networks", Int. J. Advanced Networking and Applications.

[19] Al-Maashri, Ahmed and Mohamed Ould-Khaoua, 2006. "Performance Analysis of MANET Routing Protocols In Presence Of Self-Similar Traffic" - Dept. of Electrical and Computer Engineering - Sultan Qaboos University, Sultanate of Oman, IEEE.

[20] Arun Kumar B. R , Lokanatha C. Reddy , Prakash S. Hiremath, 2008. "Performance Comparison of Wireless Mobile Ad-Hoc Network Routing Protocols “, IJCSNS International Journal of Computer Science and Network Security, VOL. 8 No.6

[21] C. E. Perkins, E. M. Royer and S. Das, 2008. "Ad Hoc Ondemand Distance Vector Routing (AODV)," IETF RFC 3561.

[22] David B. Johnson, David A. Maltz, and Yih-Chun $\mathrm{Hu}$, 2004. The Dynamic Source Routing Protocol for Mobile Ad Hoc Networks (DSR), <draft-ietf-manet-dsr-10.txt> Internet-draft.

[23] R. Thorulp, 2007. "Mobile Ad Hoc Networks and Routing Protocols," Implementing and Evaluating the DYMO Routing Protocol, Master's Thesis at the University of AARHUS, pp. 7- 20.

[24] Jose Costa-Requena ,2007. “ A Hybrid Routing Approach for Ad hoc Networks" Helsinki University of Technology, Networking Laboratory Teknillinen Korkeakoulu, Tieteverkkolaboratorio Espoo. 
[25] A. Fourati, K.A. Agha, 2006. "A shared secret-based algorithm for securing the OLSR routing protocol," LRI, IRIT, CRISTAL University Paris-SUD XI Paris, France.

[26] Network Simulator (OPNET), OPNET Technologies Inc, available at http://www.opnet.com/.
[27] X. Hong, K. Xu and M. Gerla. 2002. "Scalable Routing Protocols for Mobile Ad Hoc Networks," IEEE Network, University of California at Los Angeles. 